\title{
Non-Syndromic Oligodontia: A Rare Case Report
}

\author{
Maganur PC*, Satish V, Panda S and Dayanand \\ Saraswathi MC \\ Department of Pedodontics, College of Dentistry, Saudi \\ Arabia \\ *Corresponding author: Prabhadevi. C. Maganur, \\ Department of Pedodontics, College of Dentistry, Saudi \\ Arabia
}

Received: August 14, 2017; Accepted: October 06, 2017; Published: October 25, 2017

\section{Abstract}

Dental agenesis is the most common developmental anomaly in humans, often presenting a significant clinical problem. In the literature, some terms are used to describe missing teeth like Oligodontia, Anodontia and Hypodontia. Oligodontia is defined as the developmental absence of six teeth or more, excluding third molars. Oligodontia has a low prevalence and is a very rare condition. This paper reports a 13-year-old female patient who presented oligodontia with absence of twelve permanent teeth.

Keywords: Agenesis; Anodontia; Hypodontia; Oligodontia; Oral abnormalities

\section{Introduction}

Dental agenesis is the most common developmental anomaly in humans, often presenting a significant clinical problem. Tooth agenesis is the failure of tooth bud development, causing definitive absence of the tooth. In most populations, Polder, et al. 2004, reported prevalence of permanent tooth agenesis, excluding third molars, varies from $2.2-10.1 \%[1]$.

Majority of cases, they are present with only one missing tooth [1]. Agenesis of more than two teeth occurs in approximately $1 \%$ of the population [1]. Dental anomalies can result from many factors, including genetics and environmental. Although defects in certain genes have the highest incidence, etiological events in prenatal and postnatal periods have also been blamed for anomalies in tooth number, dimension, morphology, position, and structure [2].

The purpose of this article is to report a rare case of congenitally missing multiple teeth and review of literature.

\section{Case Presentation}

A female patient aged 13 years reported to department of Pedodontics, College of Dentistry, Jizan, Kingdom of Saudi Arabia, with a chief complaint of irregularly placed upper front teeth (Figure 1) and pain in upper right back tooth region. It was her first dental visit. Physical examination and extra oral findings were quite normal. Family history was normal. No other sibling had similar history. There was no past dental history; mother was unaware of presence of full set primary dentition. On clinical examination, patient had mixed dentition. 12 permanent teeth were clinically missing and were confirmed through OPG (Figure 2) and CBCT (Figure 3,4). Teeth present and congenital missing teeth have been illustrated in Table 1. Patient had Angle's Class I molar relation. Primary right maxillary first molar (54) and primary mandibular left first molar (74) was grossly decayed. Both mandibular central primary incisors were showing mobility. Based on clinical and radiological examinations, the case was diagnosed as Non-syndromic oligodontia. The condition was explained to the patient. A multidisciplinary [Pedodontist, Prosthodontist and Orthodontist] approach was considered and treatment plan was decided. Extraction of primary right maxillary molar (54), primary left mandibular $1^{\text {st }}$ molar (74) and mandibular primary central incisors $(71,81)$ was done in the initial visit and the patient is under follow up for the further treatment. A follow up OPG was taken after 2 months (Figure 5).

\section{Discussion}

Tooth agenesis, the congenital absence of one or more permanent teeth, is a common human anomaly. A tooth is defined to be congenitally missing if it has not erupted in the oral cavity and is not visible in a radiograph $[3,4]$.

Dental agenesis is the most common developmental anomaly in humans, often presenting a significant clinical problem. It is classified according to the number of missing permanent teeth excluding the third molars. Hypodontia is used to describe the absence of one or few teeth, Oligodontia is used for agenesis of numerous teeth (more than six teeth) excluding the third molars and anodontia is the extreme of oligodontia where there is total absence of any dental structure. Oligodontia is also known as partial anodontia, severe or advance anodontia. Some of them also refer this as selective tooth agenesis [5].

The overall prevalence of agenesis ranges from $1.4 \%$ to $11.3 \%$ in different regions and populations (Sisman, et al., 2007; Shimizu \& Maeda, 2009; Aktan, et al., 2010). According to the literature, the prevalence for oligodontia ranges from of 0.03 to $0.07 \%$ (Celikoglu, et al., 2010; Aktan, et al.). The incidence of oligodontia is reported to vary from 0.08 to $0.16 \%$. The pattern of tooth absence is influenced by the gene affected, as well as the type of mutations within the specific gene [6].

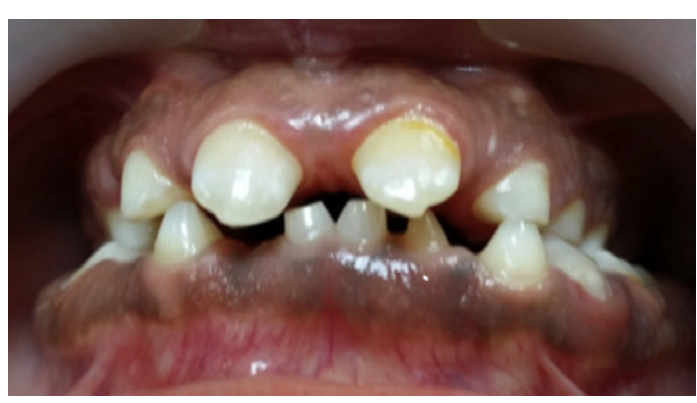

Figure 1:
Austin J Dent - Volume 4 Issue 6 - 2017

ISSN : 2381-9189 | www.austinpublishing group.com

Maganur et al. () All rights are reserved
Citation: Maganur PC, Satish V, Panda S and Dayanand Saraswathi MC. Non-Syndromic Oligodontia: A Rare Case Report. Austin J Dent. 2017; 4(6): 1090 
Table 1: Illustrating teeth present, congenital missing teeth according to *FDI or two digit system.

\begin{tabular}{|l|l|l|}
\hline & Maxillary & Mandibular \\
\hline Teeth present & $11,53,54,14,55,16,17,21,63,64,24,65,26,27$. & $71,73,33,74,34,75,36,37,81,83,44,85,46,47$. \\
\hline Congenital missing teeth & $12,13,15,22,23,25$ & $31,32,35,41,42,45$ \\
\hline
\end{tabular}

${ }^{\star}$ FDI: Federation Dentaire Internationale

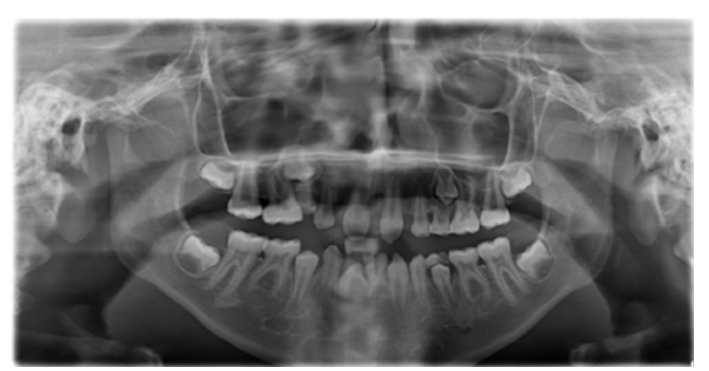

Figure 2:

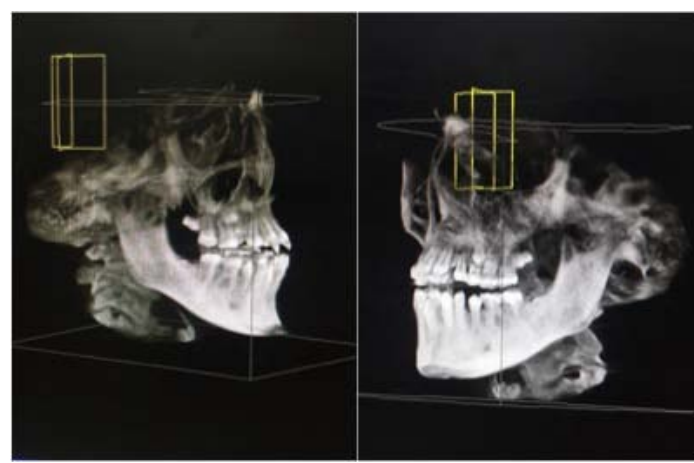

Figure 3:

Oligodontia can occur in association with various genetic syndromes, such as ectodermal dysplasia, incontinentia pigmenti, Down syndrome, Rieger syndrome, Wolf-Hirschhorn syndrome, Van der Woude syndrome, Ectodactyly-ectodermal dysplasia-clefting syndrome, cleft lip palate ectodermal dysplasia syndrome, oralfacial digital syndrome type I, Witkop's tooth and nail syndrome, Fried syndrome, hair-nail-skin-teeth dysplasias, Hirschhorn syndrome, hemifacial microsomia, and recessive incisor hypodontia [7]. When oligodontia is associated with a syndrome, there may be abnormalities of the skin, nails, eyes, ears, and skeleton.

The exact etiology for oligodontia is unknown. Various factors have been described in the literature. Heredity is the main etiological factor, several environmental factors like viral infections, toxins, and radiotherapy or chemotherapy may cause agenesis of permanent teeth. However, most of the cases are caused by genetic factors. The heritability of congenitally missing teeth has been shown in many studies. The genetic factors may be dominant or recessive and it is obvious that in many cases multiple genetic and environmental factors are acting together [8].

Heredity being major factor in Oligodontia as well as hypodontia (lack of one or more permanent teeth) are highly associated with mutations in the AXIN2, MSX1, PAX9, EDA, and EDAR genes [9]. Researchers have identified genetic defects that cause tooth agenesis either as a sole anomaly (isolated or non syndromic) or as a part of

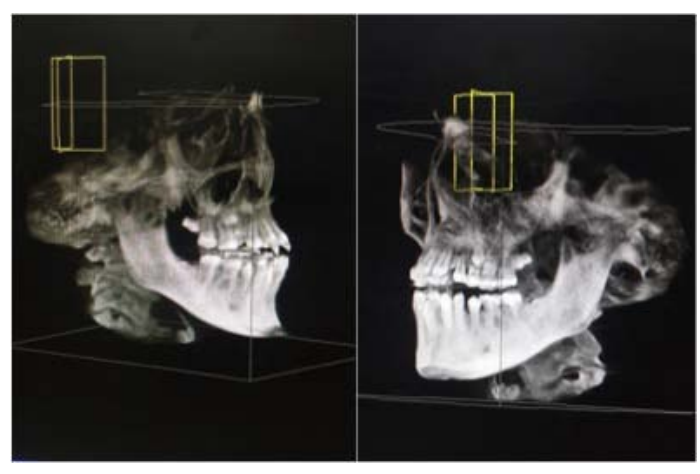

Figure 4:

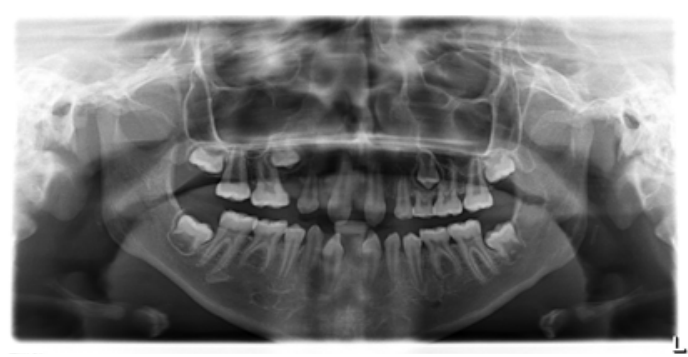

Figure 5:

multiple congenital anomalies (syndromic). One gene associated with syndromic tooth agenesis is the EDA gene (MIM\# 300451), which underlies X linked hypohidrotic ectodermal dysplasia (XLHED; MIM\# 305100). Non syndromic tooth agenesis has wide phenotypic heterogeneity and is classified as either sporadic or familial, which can be inherited in an autosomal dominant, autosomal recessive, or X linked mode (Burzynski and Escobar, 1983) [1].

Abnormal gene function may also disrupt specific signaling pathways involved in tooth development, resulting not only in abnormal tooth number but also in abnormal tooth size and or shape. Several genes and disruptions in the molecular pathways are suggested in causing defects affecting all teeth in a majority of cases presenting as oligodontia or anodontia. The genes and molecular pathway involved in tooth agenesis are Wnt/b-Catenin/LEF 1 MSX 1 MSX 2 SHH p63 Pitx 2 Runx 2/Cbfa 1 [10].

Only countable number of cases has reported with congenital missing of permanent teeth. Tsai, et al., have reported a case of oligodontia in a 6-year-old female patient with congenital absence of 16 permanent teeth [11]. Akkya, et al., in their case report of 16-yearold patient have reported oligodontia of six permanent teeth [12]. Rasmussen reported nine cases of non syndromic oligodontia with 14-24 missing teeth excluding third molar [13]. Nagveni, et al., have reported a case of non syndromic oligodontia in a 13-year-old patient with 14 missing teeth [14]. Guruprasad, et al., have reported a case of 
non syndromic oligodontia in a 9-year-old patient with 26 missing teeth [8].

In the present case, 12 permanent teeth were congenitally absent. Nearly half of the permanent dentition was absent. Treatment plan included Extraction of grossly destructed 54. Multi-disciplinary treatment plan was devised with orthodontic and prosthodontic consultation. Pulpectomy in relation to 85 and followed by Stainless Steel Crown [SSC], Intentional Pulpectomy in relation to 75 followed by SSC. The patient is under observation and follow up.

Missing teeth compromise human health, both physically and emotionally, and generally require multidisciplinary approach. Thus, clinicians should evaluate the cases carefully. Early diagnosis and treatment planning should be made for appropriate treatment modalities and to minimize the complication of these dental anomalies.

\section{References}

1. Biradar VG, Hugar SI, Biradar SV. Oligodontia: A rare case report and literature review. Saudi J Health Sci. 2013; 2: 2127-2129.

2. Borie E, Fuentes R, Beltran V. Multiple tooth agenesis in non-syndromic patient: a rare case report. Int J. Morphol. 2012; 30: 634-636.

3. Hiremath Mallayya C. Nonsyndromic Oligodontia: A Rare Case Report AOSR. 2012; 103-107.

4. Vijay kumar Biradar, Surekha Biradar. Non-Syndromic Oligodontia: Report of Two Cases and Literature Review. Int J of Oral \& Maxillofacial Pathol. 2012; 3: $48-51$.
5. Puneet Bajaj, Robin Sabharwal, Sonia Joshi. Nonsyndromic oligodontia: a rare case report with Review of literature. DJAS 2(II). 2014; 109-112.

6. Singer SL, Henry PJ, Lander ID. A treatment planning classification for oligodontia. Int J Prosthodont. 2010; 23: 99-106.

7. Cakur B, Dagistan S, Milgolu, Bilge M. Nonsyndromic oligodontia in permanent dentition: Three siblings. Internet J Dent Sci. 2006; 3.

8. Mathian VM, Gawthaman M, Karunakaran R, Vinodh S, Manikandan S, Sundaram AM. Nonsyndromic oligodontia in siblings: A rare case report. J Pharm Bioallied Sci. 2014; 6: S200-203.

9. Bergendal B, Klar J, Stecksen-Blicks C, Norderyd J, Dahl N. Isolated oligodontia associated with mutations in EDARADD, AXIN2, MSX1and PAX9 genes. Am J Med Genet A. 2011; 155A: 1616-1622.

10. De Coster PJ, Marks LA, Martens LC, Huysseune A. Dental agenesis: genetic and clinical perspectives. J Oral Pathol Med. 2009; 38: 1-17.

11. Tsai PF, Chiou HR, Tseng CC. Oligodontia--a case report. Quintessence Int. 1998; 29: 191-193.

12. Akkaya N, Kiremitçi A, Kansu O. Treatment of a patient with oligodontia: a case report. J Contemp Dent Pract. 2008; 9: 121-127.

13. Rasmussen P. Severe hypodontia: diversities in manifestations. J Clin Pediatr Dent. 1999; 23: 179-188.

14. Nagveni NB, Umashankar KV, Radhika NB, Satisha TS. Nonsyndromic oligodontia - Report of a clinical case with 14 missing teeth. BJMS. 2011; 10: $200-202$
Austin J Dent - Volume 4 Issue 6 - 2017

ISSN : 2381-9189 | www.austinpublishing group.com

Maganur et al. (C) All rights are reserved
Citation: Maganur PC, Satish V, Panda S and Dayanand Saraswathi MC. Non-Syndromic Oligodontia: A Rare Case Report. Austin J Dent. 2017; 4(6): 1090. 